\title{
Reconstrução normativa em Axel Honneth e os múltiplos justos do mercado de trabalho
}

\author{
Normative reconstruction in Axel Honneth and \\ the multiple fair and just of the labor market
}

\author{
Cinara L. Rosenfield* \\ Luciana Garcia de Mello** \\ Andressa S. Corrêa***
}

\begin{abstract}
Resumo: Esse artigo tem por objetivo analisar as contribuições de Axel Honneth para o atual debate das teorias da justiça, entre as quais a principal é a busca de princípios normativos encrustados na realidade social. Em sua obra $O$ direito da liberdade, o autor indica a liberdade como o grande valor moderno. O medium da justiça seria uma liberdade de tipo social a qual estaria expressa nas instituições vinculadas às relações pessoais, ao mercado e ao universo político. Considerando a lacuna entre os princípios normativos de justiça indicados pelo autor e a realidade social este artigo propõe colocar em discussão as potencialidades e limites da própria reconstrução normativa como instrumento de análise do social, pautando especificamente o mercado de trabalho, a fim de colaborar à discussão das possibilidades de articular a norma compartilhada e a emergência de valores em vias de institucionalização.
\end{abstract}

Palavras-chave: Reconstrução normativa. Liberdade social. Pesquisa empírica. Mercado de trabalho. Zona cinzenta.

Abstract: This paper aims to analyze Axel Honneth's contributions to the current debate on theories of justice, among which the main one is the search for normative principles embedded in social reality. In his book, Freedom's right, the author points

* Cinara L. Rosenfield é doutora em Sociologia pela Université Paris-Dauphine (Paris, França), professora do Departamento de Sociologia e do PPG em Sociologia da Universidade Federal do Rio Grande do Sul em Porto Alegre, RS, Brasil, pesquisadora do Cnpq e líder do Grupo de Pesquisa Trabalho e Reconhecimento (GteR) <rosenfield@uol.com.br>.

** Luciana G. de Mello é doutora em Sociologia em cotutela pelo PPG em Sociologia da Ufrgs e Université de Nice Sophia Antipolis (França), é professora do Departamento de Sociologia na Universidade Federal do Rio Grande do Sul em Porto Alegre, pesquisadora do Grupo de Pesquisa Trabalho e Reconhecimento (GteR)<lusociais@yahoo.com.br>.

***Andressa S. Corrêa é doutoranda do PPG em Sociologia da Ufrgs, bolsista Capes, membro do Grupo de Pesquisa Trabalho e Reconhecimento (GTeR) e do grupo de pesquisa em Economia Solidária da Unisinos<andressa_teatro@yahoo.com.br>.

Civitas, Porto Alegre, v. 15, n. 4, p. 664-685, out.-dez. 2015 
out freedom as the great modern value. The medium of justice would be a social-type freedom which would be expressed in institutions linked to personal relationships, the marketplace and the political world. Considering the gap between the normative principles of justice pointed out by the author and social reality, this paper proposes to put into discussion the potentialities and limits of the normative reconstruction itself as an instrument for analysis of the social reality, specifically addressing the labor market, in order to contribute to the debate on the possibilities of networking the shared standard and the emergence of values in process of institutionalization.

Keywords: Normative reconstruction. Social freedom. Empirical research. Labor market. Gray zone.

\section{Introdução}

Esse artigo tem por objetivo analisar as contribuições de Axel Honneth para a ampliação de uma teoria da justiça. Em sua obra El derecho de la libertad (2014), o autor problematiza as discrepâncias existentes entre os princípios normativos da justiça e a realidade social. Para superar essa lacuna, o ele propõe construir uma teoria da justiça a partir dos requisitos das estruturas institucionais das sociedades modernas. Para tal, adota como recurso metodológico a reconstrução normativa; esse instrumento permitiria analisar o que é eticamente justo no social. Nesse artigo, serão analisadas as contribuições de Honneth para a teoria da justiça e, em seguida, colocase em discussão a reconstrução normativa, examinando-a do ponto de vista teórico e de sua aplicação a estudos empíricos voltados para o mercado de trabalho.

$\mathrm{O}$ artigo está divido em três partes. Na primeira, será apresentada a trajetória do autor na construção de uma teoria da justiça, passando do paradigma da redistribuição para o do reconhecimento, para chegar a uma ideia de justiça fundamentada na existência de um acordo normativo compartilhado. Na segunda, busca-se explorar o modelo teórico-metodológico da reconstrução normativa, que possibilita a identificação dos valores compartilhados e primos na modernidade para garantir uma vida significativa a todos os sujeitos. A discussão culmina com a reconstrução normativa como articulação entre filosofia normativa e pesquisa social. Na terceira parte, tratase de compreender como a reconstrução normativa, no que tange ao conteúdo ético presente no mercado laboral, pode auxiliar a pensar o justo diante da multiplicidade atual de relações de trabalho - a chamada zona cinzenta do trabalho e emprego -, ao se lançar mão de estudos empíricos realizados pelas autoras. 


\section{Justiça: reconhecimento e instituições}

O projeto intelectual de Honneth tem como ponto de partida uma proposta de renovação da teoria crítica. Para o autor haveria importantes deficit nas abordagens de seus predecessores e, como explica Ravagnani (2009), Honneth rompe com Adorno e Horkheimer, sobretudo, por considerar que esses explicam de modo inadequado os fundamentos normativos da teoria crítica, pois reduzem o conceito de racionalidade a algo instrumental ou estratégico. Há ainda a crítica ao modo como Habermas compreende a ordem social e ao fato de que o conceito de razão desse autor leva-o a perder de vista a realidade estruturante do conflito social em relação ao mundo da vida e ao sistema. Honneth, por sua vez, distancia-se das abordagens utilitaristas e se propõe a reconstruir a gramática moral dos conflitos sociais. Assim, o autor ganhou notoriedade no campo intelectual ao eleger o conceito de reconhecimento como um elemento crucial para analisar os conflitos sociais.

Em seu primeiro livro Luta por reconhecimento: a gramática moral dos conflitos sociais (2003 [1993]), Honneth afirma que o reconhecimento é uma condição para que os indivíduos desenvolvam suas relações práticas e se autorrealizem e, consequentemente, adquiram sua autonomia. Nesse sentido, "os diversos padrões de reconhecimento representam condições intersubjetivas que temos de pensar necessariamente quando queremos descrever as estruturas universais de uma vida bem-sucedida" (Honneth, 2003, p. 273). O reconhecimento, explica Holmes (2009), seria o medium em que se daria a construção da eticidade formal na sociedade moderna. Para Honneth, a eticidade aparece como fonte última da normatividade e se torna uma ferramenta para apontar experiências sociais como patológicas, quando essas não atendem aos requisitos de uma integração saudável. Ainda segundo o autor, a apropriação do conceito de eticidade realizada por Honneth permitiria dar atenção a formas de injustiça social.

Todavia, em livro publicado mais recentemente por Honneth (2014), são os requisitos para uma ordem social justa que estão em questão e, consequentemente, a discussão sobre os fundamentos normativos da crítica ganha destaque, ficando a análise dos conflitos sociais em segundo plano. $\mathrm{O}$ autor parte do pressuposto de que a ideia de justiça na sociedade moderna está relacionada ao valor ético da liberdade; esta, por sua vez, depende da autonomia individual. Considera que houve uma fusão entre a ideia de justiça e de liberdade e, ao mesmo tempo, entre a ideia de justiça e autonomia. A busca por autonomia individual é interpretada sob o prisma de demandas por ampliação de reconhecimento recíproco. Contudo, essas demandas já não são 
analisadas tendo por foco as experiências de desrespeito e sim as instituições que permitem o reconhecimento mútuo e, consequentemente, a realização da liberdade social. Nesse processo, o reconhecimento que antes era um conceito analítico, agora se torna uma condição para pensar a justiça social. Dito isso, no que se segue, trata-se de delinear o percurso teórico do autor a fim de destacar as suas contribuições para a teoria da justiça, do reconhecimento às instituições.

Em A luta por reconhecimento (2003), Honneth concebe a integração social, nessa etapa da sua obra, não apenas em termos econômicos ou em relação à aquisição de direitos formais; mas em termos de reconhecimento. $\mathrm{O}$ indivíduo busca reconhecimento de diferentes porções de sua personalidade e, desse modo, vai desenvolvendo simultaneamente a sua identidade e relações práticas. Todavia, o reconhecimento está ancorado em uma relação intersubjetiva, que se define entre parceiros de interação. Disso decorre que existe a possibilidade de não-reconhecimento e, portanto, de desrespeito. As experiências de desrespeito são a chave interpretativa utilizada por Honneth para construir a gramática moral dos conflitos sociais. Há um entendimento de que o desrespeito priva as pessoas de sua liberdade de ação e, ao mesmo tempo, interfere negativamente na compreensão que as pessoas têm de si próprias. Assim, as experiências de desrespeito desencadeariam os conflitos sociais, compreendidos como lutas por reconhecimento, dado que o descontentamento social está associado à não confirmação social de determinados aspectos da personalidade dos indivíduos, contrariando assim suas expectativas prévias.

Fraser (Honneth; Fraser, 2006) considera que Honneth faz uma passagem muito rápida das experiências de desrespeito para a luta por reconhecimento. Segundo a autora, não se pode afirmar de modo inquestionável que dessas experiências emerjam necessariamente conflitos sociais. Ao invés de encontrar as origens sociais das injustiças, Honneth, de acordo com Melo (2014, p. 28) e seguindo o argumento de Fraser, estaria "limitado a uma 'psicologia moral do sofrimento pré-político', obrigando a teoria a determinar seu referencial normativo a partir da expectativa de reconhecimento da identidade pessoal". $\mathrm{O}$ autor reconhece esse problema e faz um esforço subsequente de construir uma teoria da ação e uma teoria da justiça. Assim, a ideia de esboçar uma teoria da justiça vincula-se à necessidade de explicitar a precedência ontológica das relações de reconhecimento.

A singularidade da abordagem de Honneth se faz notar quando se analisa o modo como esse autor aborda as questões de justiça. Se, por um lado, há uma aceitação da ideia atualmente vigente de que a possibilidade de autonomia individual é o elemento essencial da justiça na modernidade; por 
outro, há importantes divergências sobre o modo como essa autonomia deve ser assegurada e garantida. O problema levantado por Honneth $(2004 ; 2009)$ é que as abordagens que vinculam a autonomia à posse de determinados bens básicos, materiais ou simbólicos, trazem como consequência a ideia de que o material da justiça são bens amplamente estimados. Disso decorre igualmente que uma ordem social justa depende de uma justa distribuição de bens básicos. Honneth quer justamente chamar a atenção para as relações de reciprocidade, algo que não pode ser simplesmente assimilado no esquema significativo de distribuição de bens:

Para poder perceber a disposição sobre dinheiro como chance de liberdade, numa pessoa precisam estar formadas primeiro concepções sobre objetivos dignos de serem almejados, para poder compreender chances profissionais como caminhos para a realização das habilidades individuais, a pessoa primeiro precisa ter compreendido suas disposições e talentos como importantes e dignos de realização. Nenhum destes pressupostos necessários possui a forma de um bem fixo, eles não podem ser simplesmente "possuídos" como "coisas", mas precisam ser penosamente adquiridos em e através de relações entre pessoas (Honneth, 2009, p. 353).

Há uma limitação no esquema distributivo, seguindo Honneth, pois é preciso supor uma autonomia prévia do sujeito para que os bens sejam considerados como meios significativos para a realização da liberdade individual. As condições para autonomia pessoal só podem ser encontradas nos próprios sujeitos e nas relações sociais que estes estabelecem. Rompendo, portanto, com essa interpretação, Honneth argumenta que a autonomia é alcançada por vias intersubjetivas. Isso significa que a autonomia não pode nos ser outorgada pela posse de bens e sim necessita do reconhecimento recíproco entre sujeitos.

Uma vez estabelecida a ruptura com o paradigma distributivo, a próxima etapa da abordagem de Honneth consiste em rediscutir o conceito de autonomia. A adoção de uma concepção liberal e individualista de autonomia pelas teorias da justiça é vista como problemática. Tal concepção fundamentase em uma transformação histórica, que marca o início do período moderno. Nessa fase, a noção de autonomia foi pensada como desprendimento de determinados laços sociais e de papéis sociais tradicionais. Autonomia passou a relacionar-se essencialmente à questão dos indivíduos poderem desenvolver, sem obstáculos, os objetivos pessoalmente escolhidos (Anderson; Honneth, 2011, p. 83). Quanto menos constrangimentos se apresentarem à ação dos 
indivíduos, tanto maior sua liberdade e sua autonomia. Para os autores, essa ideia apresenta dois problemas principais: a) introduz a ideia de que os indivíduos alcançam a autonomia ao obterem independência de seus parceiros; b) considera-se que toda e qualquer constrição reduz a autonomia do indivíduo.

As teorias da justiça, justamente por terem por base essa noção de autonomia, interpretam as exigências de justiça social como eliminação de interferências à realização pessoal. Logo, não se consegue tratar de forma adequada carências, vulnerabilidades e interdependência dos indivíduos. Faz-se necessário compreender a autonomia de outra maneira: "autonomia é uma capacidade que existe somente no contexto das relações sociais que a asseguram e somente em conjunção com o sentido interno do que significa ser autônomo" (Anderson e Honneth, 2011, p. 85). As relações de reconhecimento recíproco são consideradas componente fundamental da autonomia individual e tornam possível pensar nas exigências de justiça social, rompendo com o materialismo. O ponto de partida é levar em consideração que a autonomia plena só pode ser alcançada sob condições sociais favoráveis.

O procedimentalismo das teorias da justiça é igualmente colocado em xeque por Honneth $(2004 ; 2006 ; 2009)$. Se os bens são a matéria da justiça, torna-se difícil imaginar os sujeitos em condições equitativas e imparciais para que consigam tomar decisões sobre princípios justos, como já explicitado. Honneth chama atenção para o fato de que esse procedimento pressupõe indivíduos autônomos e parte de uma ideia de distribuição de bens que não é factual. $\mathrm{O}$ autor sugere que as condições contextuais do procedimentalismo sejam pensadas a partir de outro material: as relações sociais recíprocas. Diferentemente dos bens materiais, as relações de reconhecimento não podem ser coisificadas, não podem ser alocadas de forma aleatória, não são fixas e sequer são previamente determinadas. Ao mesmo tempo, não se pode dispor livremente dessas relações, dado que elas são construtos sociais e não pertencem aos indivíduos.

Honneth, em $O$ direito à liberdade (2014, p. 20), argumenta que não se deve aplicar à realidade princípios de justiça obtidos de forma imanente, tampouco se deve pressupor a realidade social como um objeto já suficientemente analisado. O autor, seguindo Hegel, retoma o conceito de eticidade para chamar a atenção para a rede de rotinas e obrigações que se relacionam com certas atitudes morais enquanto práticas sociais, isto é, enquanto valores institucionalizados socialmente. Assim como Hegel, Honneth emprega o conceito de eticidade de modo seletivo, tipificador e normativo, 
para realizar uma reconstrução normativa. ${ }^{1}$ Cumpre destacar que o conceito de eticidade para Hegel não se aplica à multiplicidade de formas de vida ética presente na sociedade, mas tão somente

[...] aquello que probadamente pudiera servir para ayudar a realizar los valores e ideales generales de las sociedades modernas; todo lo que contradijera estos requisitos normativos, todo lo que representara valores particulares o encarnara ideales retrógados, ni se lo consideraba digno de convertirse en objeto de la reconstrucción normativa (Honneth, 2014, p. 22).

Honneth admite que o conceito de eticidade de Hegel parece apontar para se afirmar o que já existe, dado que somente pode valer como ético o que nas formas sociais de vida encarne um valor geral; mas considera possível associar a ele metas corretivas e transformadoras. Nesse caso, haveria uma passagem da reconstrução normativa para a crítica reconstrutiva, quando já não se trata apenas de contrapor instituições e práticas com determinados padrões externos de justiça, mas utilizar esses mesmos padrões para denunciar uma insuficiente ou incompleta encarnação de valores geralmente aceitos. Desse modo, os juízos normativos não possuem um caráter categórico e sim gradual. Critica-se em cada caso como uma instituição, vista como ética, poderia representar melhor ou de maneira mais completa a ampliação de valores que servem para a reconstrução da eticidade.

Portanto, para Honneth, o medium da justiça é determinado a partir de uma reconstrução normativa da eticidade predominante em uma sociedade. Para dar conteúdo a essa eticidade, o autor se utiliza de um procedimento teórico-metodológico que considera a racionalidade moderna, de um lado, e as práticas sociais existentes, de outro. São os seguintes os princípios que fundamentam este assim chamado procedimento teórico-metodológico para determinação do justo: existem valores gerais racionais compartilhados em uma sociedade; o justo deve ser pensado em relação a esses valores; é necessário encontrar na realidade social as instituições nas quais esses valores são efetivados; há ainda a possibilidade da crítica às instituições existentes quando as mesmas não encarnam os valores generalizados. É este o caminho que torna possível dar conteúdo à eticidade moderna, tendo na reconstrução normativa seu principal instrumento.

\footnotetext{
${ }^{1} \mathrm{Na}$ seção seguinte deste artigo apresentaremos uma discussão mais detalhada sobre esse instrumento teórico-metodológico.
} 
Honneth aposta na reconstrução normativa para elaborar uma teoria da justiça e para avançar em importantes questões surgidas desde a teoria do reconhecimento. Através desse instrumento teórico-metodológico, o autor logra: a) apontar a existência de um acordo normativo compartilhado, que constitui o fundamento da justiça; b) abordar o justo como construção social e assim superar o abismo entre a filosofia política e a práxis social; c) mobilizar as relações de reciprocidade como matéria da justiça. Esses avanços permitiriam assim analisar as condições de autorrealização individual presentes na ordem social das sociedades modernas e investigar as condições necessárias para realmente possibilitar a autonomia do indivíduo. Assim, o processo de reconstrução enseja analisar como determinados valores e ideias se institucionalizaram. Na etapa seguinte desse artigo nos deteremos sobre o modelo teórico metodológico de reconstrução normativa.

\section{Potencialidades teórico-metodológicas da noção de reconstrução normativa}

A noção de reconstrução normativa, proposta na obra de 2014, vem responder algumas das principais reflexões críticas à teoria honnethiana já tecidas (Rosenfield; Saavedra, 2013): a) o caráter supostamente individualizante da teoria do reconhecimento; b) as dificuldades da relação entre proposta normativa e fundamentação empírica da teoria. Em relação à primeira crítica, o autor alega que o valor ético que perdura nas sociedades modernas é o valor da liberdade entendido como autonomia individual. A noção de autonomia seria capaz de estabelecer um elo sistemático entre o individual e a ordem social, sendo que a justiça social pressupõe reflexões sobre como se instituir uma sociedade em que caibam os interesses e necessidades de seus integrantes (Honneth, 2014, p. 30). E ambas as críticas são respondidas ao propor um caminho metodológico de articulação entre estruturas institucionais que emergem de sociedades concretas e a ordem da justiça, de maneira a permitir a todos os sujeitos participantes questionar a norma ou por não estar sendo cumprida ou porque deve ser transformada em função das modificações dos valores e das práticas sociais imperantes já em curso, uma vez que a imagem de liberdade e justiça se transforma ao longo do tempo. O autor integra a possibilidade de haver vários modelos de liberdade e de construção de uma ordem justa.

Para Honneth, o valor comum existente na modernidade que encarnaria o normativo compartilhado seria a liberdade. Constata, no entanto, a existência de diferentes interpretações para o conceito, as quais podem ser resumidas em três perspectivas de liberdade: a negativa, a reflexiva e a social. A cada 
uma destas formas corresponde um modelo de justiça, em ordem crescente de complexidade. A liberdade negativa baseada, sobretudo, em Hobbes, remete à ausência de impedimentos externos para que os indivíduos realizem os objetivos a que eles mesmos se propuseram. Desta postura, elabora-se uma justiça caracterizada pelo egoísmo, na qual o direito restringe liberdades em favor de uma convivência pacífica em que cada um possa levar a cabo seus interesses oriundos da natureza ou do espírito.

A liberdade reflexiva se caracteriza pela capacidade do sujeito de determinar a si mesmo, para além de sua natureza, ou seja, de suas paixões ou interesses. Rousseau seria seu grande inspirador, habilitando os sujeitos a tomarem decisões próprias, examinarem seus motivos, colocarem as formas institucionais em questão. Esta concepção integraria duas posições: autolegislação e autenticidade, derivando somente da primeira uma concepção de justiça, a procedimental. Nesta, parte-se de um sujeito racional atomizado (Kant) ou de um processo comunicativo (Habermas), sendo o consenso construído com vistas a possibilitar a expressão das liberdades individuais, ou dos grupos, sem uma construção ética conjunta. A perspectiva se caracteriza como formal, sem conteúdo, já que o privilégio é dado a um procedimento, no qual todos os grupos ou sujeitos tenham igualdade de condições para participar na construção da vontade. Mais uma vez a justiça deriva de princípios abstratos pré-estabelecidos, a saber, igualdade de status entre os diferentes sujeitos e grupos.

Por fim, o autor elabora os elementos constitutivos de uma liberdade social, através da qual os objetivos autodeterminados dos diferentes sujeitos se confirmam e se ampliam mutuamente. Logo, esta liberdade se efetivaria a partir do reconhecimento recíproco em diferentes esferas da vida, de maneira que os sujeitos logram se perceber como socialmente confirmados. Esta perspectiva se materializa na realidade social a partir das instituições (entendidas como conjunto de costumes, práticas) nas quais se toma consciência, no processo de socialização, da dependência mútua.

Para entender o justo é necessário identificar as instituições da modernidade que encarnam a capacidade de reciprocidade, de reconhecimento, de construção conjunta. Evidencia-se nesta perspectiva a experiência social, considerando que há uma eticidade inscrita na realidade que permite avaliar o justo a partir da relação entre as necessidades do sujeito e seu entorno intersubjetivo concretizado nas instituições. A justiça não pode ser alcançada nem pelo contrato, nem pelo procedimento. O primeiro, típico da liberdade negativa, nega a subjetividade em favor de uma ideia de natureza egoísta dos sujeitos. O segundo, típico da liberdade reflexiva, nega a objetividade, pois 
ignora que o procedimento é resultado de uma construção coletiva e não seu ponto de partida. A interação entre os sujeitos precede aos distanciamentos colocados na esfera jurídica ou da consciência, características das outras liberdades. Assim, importam para a liberdade social as formas de ação comunicativa inscritas na realidade social a partir das instituições que confirmam o vínculo, pois uma existência justa depende de uma cultura da complementaridade erigida sobre normas de ação compartilhadas.

Em outras palavras, a liberdade social significa a liberdade existente na ação relacional, na qual a consideração e o reconhecimento recíprocos constituem condição necessária para a realização dos próprios objetivos de ação. Remete aos sistemas de ação em que os participantes só logram colocar em prática se realizados cooperativamente ou em conjunto. Através da liberdade social os indivíduos exercem o direito de verificar individualmente se as instituições existentes satisfazem aos seus próprios padrões instituídos e para isto necessitam também da liberdade negativa (que se concretiza na liberdade jurídica) e da liberdade reflexiva (que é uma liberdade moral). A liberdade negativa tomou, na realidade, a forma de liberdade jurídica, garantida pelo estado. A liberdade reflexiva a forma de uma liberdade moral, outorgada intersubjetivamente. A liberdade social é a concretude da liberdade e tem como base o reconhecimento mútuo. A ela se devem as condições de existência das outras duas formas de liberdade. Ao passo que as liberdades negativa e reflexiva são reguladoras, a liberdade social remete aos sistemas de ação cooperativos ou coletivos.

A reconstrução normativa encontrou nos três tipos de liberdade formas de efetivação do normativo compartilhado moderno. Dito isso, a reconstrução normativa congregaria as metas que se deveria seguir racionalmente, junto às experiências e circunstâncias históricas, fundando um procedimento teóricometodológico de enorme potencial para o julgamento acerca do justo. Chegase, assim e seguindo Hegel, "[...] casi em forma de determinaciones típicas ideales, aquellas metas que persiguen los sujetos situados historicamente como seres razonables em la Modernidad" (Honneth, 2014, p. 82). Trata-se, pois, de "encontrar" na realidade os acordos coletivos, institucionais, em termos de reconhecimento recíproco, para indicar onde há e onde não há a efetivação da liberdade social. Segundo Honneth, cabe indagar o significado de que "[...] distintas prácticas constituyan juntas la unidad de uma institución que sirve a la satisfacción recíproca de propósitos individuales" (p. 89). A reconstrução normativa permite aferir se estas práticas significam padrões de atuação coletiva e quais os conteúdos das categorias ali existentes de obrigação mútua. A construção de uma ordem justa, ou seja, de um sistema 
institucional que garanta a liberdade de tomada de decisão pelos sujeitos, pressupõe, antes de tudo, uma estrutura institucional e reconhecimento para, a posteriori, os indivíduos criticarem e tomarem decisões em relação à ordem já posta. A possibilidade de mudança decorre da relação entre objeção individual e realidade institucional. As instituições éticas possibilitam a autonomia individual que, por sua vez, quando acionada, coloca em questão essas instituições.

Vemos, pois, uma proposição para escapar da armadilha de se restringir a uma concepção de liberdade em uma fundamentação de princípios unicamente formais e abstratos. Assim, o autor argumenta que: 1) o caminho metodológico da reconstrução normativa significa a "exposición de una concepción de la justicia diretamente por la senda de uma reconstrucción del desarrollo social guiada por lo normativo" (Honneth, 2014, p. 91). Para tal, faz-se necessário uma comparação normativa com a história prévia para se chegar aos princípios e normas que estejam em vigência social; 2) a teoria da justiça necessita "atravessar a fronteira com a matéria social". A justiça decorre da realidade social, e é na articulação entre liberdade e sistema institucional correspondente que se realizam as condições de dotar a sociedade da maior liberdade possível. Nas práticas institucionais é que se realizam as experiências de reconhecimento entre sujeitos de maneira regulada normativamente. As instituições normativas são instituições éticas que propiciam garantia jurídica, proteção estatal e apoio da sociedade civil.

É este argumento que remete à operacionalidade do conceito de reconstrução normativa. A ideia é a construção de uma ordem justa a partir da estrutura institucional existente e não como um modelo prévio a ser aplicado à realidade para mensurar o quanto esta realidade está próxima ou distante do modelo. A justiça não pode ser compreendida independentemente dos valores e ideias gerais compartilhados no seio de uma sociedade. Baseado em Hegel, Honneth estabelece três áreas institucionais que seriam importantes na modernidade, e nas quais se garantiriam formas de reconhecimento mútuo: as relações pessoais (amizade, relações íntimas e família); a economia de mercado (esfera do consumo e o mercado de trabalho); e a esfera públicopolítica (vida pública e estado de direito). Para cada uma destas esferas ele identifica o conteúdo do reconhecimento mútuo imperante, como promessas morais e, posteriormente, analisa o quanto estes consensos morais estariam sendo efetivados na realidade social. Em relação à efetividade da liberdade social, o autor demonstra que nas relações pessoais haveria um avanço em termos de liberdade social, entretanto, no mercado e no espaço público-político há uma grande diferenciação entre as perspectivas morais de reconhecimento 
e os desenvolvimentos históricos, principalmente nas últimas décadas. Em linhas gerais, aponta que no mercado teríamos a concorrência em detrimento da cooperação e no campo político uma espécie de apatia. Tais elementos estariam se refletindo em atomização e anomia social, a partir das quais se coloca em perigo a própria liberdade social.

Observa-se que a reconstrução normativa parte de uma análise histórica e não de uma razão abstrata. Ou seja, a construção da existência de uma liberdade social tem seu fundamento no real calcado no respeito mútuo intersubjetivo. Mas o normativo torna-se então universal, é a parte racional da modernidade; a liberdade social, nesse sentido, não é transcendental, mas é um padrão universal para as sociedades modernas. Assim, o que propõe o modelo é reconstruir o conteúdo e não questionar a racionalidade intersubjetiva. O tipo quase ideal é um modelo prévio que na reconstrução normativa, no confronto com o real, se atualiza e se transforma em conteúdo, mantendo sempre o modelo enquanto padrão de liberdade social. O conceito chave para incorporar novos conteúdos à norma é o de crítica. Esta pode ser acionada quando as instituições deixam de efetivar a liberdade social. Entretanto, é importante observar que valores emergentes são integrados ao modelo de justo através da reconstrução normativa, sem contudo ficar clara a perspectiva de mudança na norma do modelo de justo, no qual o valor universal da liberdade social compartilhada permanece intocado.

Decorrem daí as dificuldades de estabelecer uma verdadeira relação dialética entre teoria e pesquisa, como será mais detidamente analisado na parte seguinte desse artigo. Voirol (2012) chama a atenção, a partir do exame das obras de Horkheimer e Habermas, precursores da noção de reconstrução normativa na Teoria Crítica e salientando a importância dada por Honneth à pesquisa social em suas elaborações filosóficas, para as dificuldades dessa articulação. Vê-se a necessidade de superar a utilização da pesquisa social como descrição empírica do projeto normativo-filosófico.

Embora as grandes dificuldades de juntar numa única estrutura teórica as questões normativas tratadas pela filosofia moral e social, de um lado, e as pesquisas sociais realizadas pelas ciências empíricas, de outro, não resultem somente das simples questões teóricas discutidas acima - em razão das restrições institucionais e acadêmicas que atualmente organizam as pesquisas sociais -, certas concepções específicas podem contribuir mais do que outras para esse fenômeno. Uma dessas dificuldades reside na situação teórica da filosofia normativa, de um lado, e na das ciências sociais, de outro. Desde a "mudança de paradigma" na filosofia política (encorajada por John Rawls no seu Teoria da justiça), que passou 
a lidar com meras questões normativas sem referência a práticas efetivas descritas pelas ciências sociais (mudança essa que também influenciou o desenvolvimento da Teoria Crítica), ficou cada vez mais difícil conceber e defender uma dialética da teoria e pesquisa. Além disso, a ultraespecialização das ciências sociais empíricas e a sua completa rejeição de temas normativos, bem como das abordagens filosóficas, dificultam ainda mais essa cooperação (Voirol, 2012, p. 97-98).

Para superar essas dificuldades, Voirol propõe que: a) a pesquisa empírica busque explicitar práticas emancipatórias nas atividades concretas atuais e também as condições sociais, econômicas, institucionais e políticas de realização eficaz dessas práticas emancipatórias; b) se faça a íntima articulação entre método reconstrutivo e diagnóstico do presente a fim de "investigar as tendências atuais nos termos da possível realização de potenciais emancipatórios baseados em práticas eficazes" (p. 98); 3) se estabeleça uma relação dialética entre teoria e pesquisa, sendo que esta última possa “sempre ter um 'poder restritivo' de redefinir construções teóricas e oferecer possibilidades para novos diagnósticos” (p. 99).

É nesse sentido que na parte seguinte será proposta a análise de valores proeminentes na esfera do mercado de trabalho especificamente, de maneira a refletir sobre as possibilidades de transformação da norma do que é justo na sociedade moderna, a partir da pesquisa empírica.

\section{Liberdade social e trabalho: os desafios para a construção de uma ordem justa}

Nesse momento, busca-se compreender como a reconstrução normativa de Honneth, no que tange ao conteúdo ético apontado pelo autor no mercado laboral, pode auxiliar a pensar o justo diante da existência de uma zona cinzenta do trabalho e emprego (Kesselman e Azaïs, 2011), que remete ao embaralhamento das tradicionais fronteiras do trabalho assalariado. Com este movimento, pretende-se trabalhar com as construções de Honneth em um grau menor de abstração - a do conteúdo ético do mercado -, a partir do qual sua aplicação, enquanto instrumento de análise do real, pode ser problematizada. Nas pesquisas sociológicas frequentemente nos confrontamos com uma diversidade significativa de práticas sociais, as quais se distanciam do padrão normativo nas diferentes instituições, vinculado à liberdade social, apontado por Honneth. Trata-se aqui de refletir sobre a possibilidade de uma análise que incorpore o real, no sentido de perceber regimes de ação emergentes que possam coexistir com as institucionalidades ou mesmo transformá-las. 
Honneth (2014) inicia a discussão do mercado identificando duas perspectivas a respeito de sua compreensão que concorrem na história do capitalismo. De um lado, considera-se o mercado destituído de acordos morais, pois orientado pela relação entre oferta e demanda a partir de cálculos de benefícios. De outro lado, partindo-se de Hegel e Durkheim, o mercado seria um espaço moral que evidencia, na sociedade moderna, a complementaridade entre os sujeitos. De maneira sintética, no mercado, a liberdade, valor fundante da modernidade, é expressa ou a partir de sujeitos atomizados orientados por um comportamento estratégico ou em "términos de pares en la comunicación que se relacionan intersubjetivamente" (Honneth, 2014, p. 233). Esta segunda postura seria a concretização da liberdade social e, sendo esta estruturante da própria sociedade, compreender o mercado em termos de complementariedade expressaria a correta conduta para se viabilizar a liberdade.

Honneth defende que a liberdade social, no que tange ao mercado, integra uma perspectiva funcionalista normativa na qual a cooperação é o marco fundamental, para além do contrato jurídico. Para aprofundar a normatividade inerente ao mercado Honneth mobiliza ainda os argumentos de Polanyi e Parsons. O primeiro indica os critérios para avaliar a normatividade do mercado, via as injustiças denunciadas pelos contramovimentos, os quais buscam, através do estado, colocar limites ao mercado, devendo este ser subordinado à sociedade democrática. O segundo demonstra a dependência do sistema à norma a partir do mercado de trabalho, e assim elenca duas dimensões fundamentais: o contrato (o trabalhador espera reconhecimento simbólico e comprometimento duradouro; a empresa espera lealdade e responsabilidade), e o papel profissional (na formação, o sujeito apropria-se do valor da eficiência que rege o mundo laboral e espera satisfação psíquica e autoestima ao cumprir suas obrigações profissionais).

Pode-se, pois, inferir que na perspectiva do autor o funcionamento do capitalismo estaria determinado pelo cumprimento de imperativos extraeconômicos. Sendo o mercado uma instituição na qual está inscrita a liberdade social, os princípios que devem limitar o intercâmbio seriam aqueles que permitam o benefício comum a partir da cooperação, na qual as intenções individuais são articuladas ao conjunto. Para encontrar tais instituições no social e empenhar sua reconstrução normativa, Honneth irá buscar a "cooperação e solidariedade" nos mecanismos discursivos e nas reformas jurídicas da esfera do consumo e do mercado de trabalho. No que segue, explora-se somente o mercado de trabalho, pelo fato de se constituir a matéria das pesquisas empíricas das autoras, a partir do qual será analisado o procedimento de reconstrução normativa. 
Como indicativos da existência dessa compreensão moral sobre o mercado na realidade, Honneth retoma a história das lutas trabalhistas e sua vinculação com os valores da sociedade democrática. Aponta os direitos trabalhistas (que garantiam estabilidade e segurança), as reformas da educação (para possibilitar iguais chances no mercado laboral) e as demandas pela humanização do trabalho (no que tange à eliminação das tarefas repetitivas e a necessidade da gestão compartilhada para moderar os interesses de maximização de lucro), como marcos do progressivo entendimento do mercado como projeto social: "se conpartía la creencia de que el mercado económico debería beneficiar a todos los participantes y, entonces, debía ser entendido como una institución de la libertad social" (Honneth, 2014, p. 335).

Entretanto, tal perspectiva teria entrado em colapso a partir dos anos 70, fato que fica explícito na retração dos salários, na precarização da contratação e na inseguridade estrutural do mercado (Honneth, 2014, p. 339). Assim, o mercado de trabalho capitalista teria se tornado injusto, se comparado com sua inserção numa sociedade salarial, na qual estaria institucionalmente calcado em princípios de estabilidade e direitos para todos. A perda de referenciais coletivos é interpretada pelo autor como uma anomalia da sociedade moderna, ou seja, um desenvolvimento "errado" do social, devendo ser recuperados, no mercado de trabalho, os princípios da liberdade social.

Diante desse diagnóstico, Honneth (2014) aponta que não se apresentam movimentos sociais utilizando a gramática moral fundada na liberdade social para se contrapor aos desenvolvimentos do mercado de trabalho. Esta situação, mesmo sendo considerada injusta pela maioria da população, não se configura como substrato motivacional para a mobilização, no que tange a demandar do mercado de trabalho suas promessas normativas de bem estar para todos. Dentre outras variáveis, como a falta de tradição histórica de lutas laborais no campo dos serviços, o autor aponta como hipótese, para explicar "la irritante desaparición de toda "indignación"” (Honneth, 2014, p. 337), a emergência de uma cultura da autorresponsabilidade, na qual o mercado passa de "un organismo social, sobre el que nosotros juntos tenemos responsabilidad como miembros de una comunidad de cooperación" (Honneth, 2014, p. 337), para um espaço de concorrência, no qual cada um deve otimizar seus benefícios. A liberdade perdeu sua dimensão social e torna-se cada vez mais individual, dado que é acessível somente para alguns trabalhadores. A autorresponsabilização não se constitui como um projeto coletivo de liberdade social.

Em termos de conteúdos éticos, tem-se como manifestação da liberdade social o acordo normativo decorrente das conquistas trabalhistas da primeira metade do século 20, representadas pelo trabalho industrial: seguro, masculino, 
assalariado e qualificado (Honneth e Fraser, 2006). Para o autor, o fim da sociedade salarial é problemático, pois não garante ao trabalhador um contrato digno (o qual inclui boa remuneração e status) e um estado de proteção (no qual se compartilha a responsabilidade do reconhecimento e da inserção de todos). Entretanto, é possível explicar o real e pensar em justiça a partir da liberdade social presente na sociedade salarial quando ela se encontra em processo de erosão no real? A referência é o tipo de relação que se estabeleceu entre os trabalhadores e a classe capitalista, relação essa que permitia uma socialização do mercado de trabalho. Atualmente há uma diversidade de modos atomizados de inserção na esfera laboral, o que enfraquece o caráter social do mercado de trabalho. Estas diferenciações encontram-se na origem do embaralhamento das fronteiras salariais e da constituição de uma zona cinzenta (Kesselmann e Azaïs, 2011), relativa às novas relações de trabalho e emprego. Esta zona cinzenta exige tanto a revisão quanto a criação de novos conceitos no âmbito da sociologia do trabalho.

Dentre as formas emergentes de inserção pelo trabalho, destaca-se o autoempreendedorismo como objeto emblemático de uma relação de trabalho em substituição a uma relação de emprego. O autoempreendedorismo é emblemático de uma forte autonomização do trabalhador, definido por uma relação de trabalho e não mais de emprego, dando lugar a combinações variadas de tempo, espaço e ação (Tripier, 1998). No que tange às suas características, no autoempreendedorismo encontram-se trabalhadores formais, outros informais; uns proprietários dos meios de produção, outros não; uns autônomos, outros completamente subordinados; uns trabalhando criativamente, outros repetitivamente; uns imersos na zona cinzenta por opção, tendo abandonado empregos seguros; outros sem opção, buscando o retorno ao assalariamento e sua seguridade. O que une a todos é o autoempreendedorismo, ou seja, o não assalariamento formal e a prestação de serviço autônoma, formal ou informal. Em termos teóricos e analíticos, o autoempreendedorismo emerge de uma conjuntura sócio-histórica de fragmentação do modelo fordista e de crítica à subordinação típica do assalariamento. As políticas públicas de incentivo ao autoempreendedorismo declaram não haver a intenção de fragilizar as relações de trabalho, contudo é inegável que elas surgem no rastro do aumento das precariedades, da diminuição da renda dos trabalhadores e da crise do emprego.

Quando a relação salarial é ausente e substituída pelo empreendedorismo, torna-se possível identificar um novo ethos capitalista no que concerne às maneiras de produzir e criar valor. Os trabalhadores autônomos são remunerados por clientes que demandam trabalho. Os limites entre autonomia e subordinação, entre inserção pelo trabalho exitoso ou precário tornam-se móveis e 
imprecisos. Nesse sentido, se o objetivo institucional das políticas se insere em uma matriz de valorização do empreendedorismo, da independência, e da autonomia, os usos dos dispositivos são, quando confrontados com as realidades múltiplas, variáveis e incertos (Rosenfield et al., 2014, p. 201).

Os estudos parecem apontar para uma realidade ambivalente, a qual não se reduz nem à precariedade, nem à virtuosidade. Seguindo o modelo honnethiano, o que importa observar nessas manifestações seria em que medida elas realizariam a liberdade social, para a qual estão em jogo valores como cooperação, reconhecimento recíproco, obra comum, relação com estado e sociedade civil. Quando tais valores não se efetivam nas experiências, urge categorizá-las como anômalas e realizar a sua crítica para que retomem o "caminho correto". Assim, buscando traçar conclusões relativas à presença ou não de liberdade social nessas novas configurações, apontam-se os valores que ganham proeminência na zona cinzenta. A partir de nossos estudos empíricos, ${ }^{2}$ assim como de argumentos anteriormente apontados pelo autor (Honneth, 2006), os valores em destaque no mercado de trabalho contemporâneo seriam a autonomia e a autenticidade, os quais não lograram ser atendidos de forma plena em contextos de assalariamento.

É valorada pelos autoempreendedores uma autonomia operacional (Rosenfield; Alves, 2011), ou seja, autonomia de gestão do tempo e autonomia em relação ao próprio processo de trabalho. A não subordinação a um horário pré-determinado, a incorporação dos filhos e da família na rotina do trabalho, o tempo livre para realização de outras atividades vinculadas ao cuidado do corpo e da mente etc. parecem se tornar um elemento fundamental da vida boa. Isso inclui a não subordinação a um conjunto de normas e a um superior ao qual se deva explicações. Assim, é possível perceber nos estudos empíricos relativos à zona cinzenta que, para muitos trabalhadores, na desvinculação ao assalariamento há um ganho de autonomia em termos de autodeterminação e gestão do trabalho.

\footnotetext{
${ }^{2}$ As reflexões empenhadas nos próximos parágrafos, assim como os exemplos de casos empíricos posteriormente indicados, provêm de pesquisas realizadas pelas autoras: 1) Cinara Rosenfield escreve a partir de entrevistas realizadas no âmbito de um projeto de pesquisa sobre a comparação da "zona cinzenta" do trabalho e emprego no Brasil, França e Estados Unidos, financiada pela Agence Nationale de Recherche, intitulada "Vers des zones grises de l'emploi?", sob a coordenação de Donna Kesselman; 2) além disso, indicam-se elementos oriundos de entrevistas realizadas por Andressa Corrêa no âmbito de sua tese de doutorado (em andamento) intitulada "O 'cultivo de si' como cultivo do mundo: um estudo sobre a contribuição social pelo trabalho de sujeitos que vivem em comunidades alternativas"; finalmente, 3) Luciana Mello traz elementos de sua tese de doutorado, intitulada "A luta do rochedo contra o mar: integração e racismo nos mercados de trabalho do Brasil e da França", defendida em 2010.
} 
Além da autonomia, outro valor que emerge a partir da década de 80 (Honneth, 2006; Taylor, 1994) e se constitui como central na relação com o trabalho é a autenticidade. O sujeito tem a necessidade de expressar no trabalho uma parte de si mesmo. Essa demanda não era garantida nas organizações devido a sua alta burocratização, ao foco na lucratividade e à instrumentalização da própria autenticidade (Honneth, 2006). O autoempreendedorismo pode constituir-se como uma solução para a expressão genuína da autenticidade, pois o trabalho torna-se uma forma de manifestação das escolhas valorativas realizadas na trajetória de vida. O ideal moral abrange a quebra dos padrões estabelecidos, principalmente os vinculados à produtividade e ao status. A satisfação no trabalho se efetiva por multiplicar seus ideais de vida e ver os resultados nos benefícios produzidos pela ação laboral, em uma relação imersa em reciprocidade.

Como exemplos do autoempreendedorismo emblemático da zona cinzenta seguem-se as indicações de casos empíricos que demonstram o embaralhamento de fronteiras canônicas do mercado de trabalho, tais como autonomia-subordinação; formal-informal. Os autoempreendedores estão divididos em dois tipos: aqueles que buscam autonomia operacional em suas inciativas, e aqueles que ainda buscam autenticidade no trabalho aliada à autonomia operacional. No primeiro grupo há o trabalhador que emprega familiares em suas cinco máquinas de corte de couro e trabalha para uma empresa terceira da indústria calçadista na completa informalidade, mas com faturamento de pequena empresa; ou a educadora que monta uma empresa e vende cursos de pós-graduação para faculdades (que entram só com a chancela do diploma). Já no segundo grupo, inclui-se o exemplo do advogado e político de carreira que se torna acupunturista, buscando promover novas formas de saúde; ou do engenheiro de produção e executivo de uma grande empresa que se torna astrólogo, buscando associar a essa nova profissão uma perspectiva budista de auxílio aos outros. Ainda inclui-se na zona cinzenta o trabalhador que deseja voltar ao assalariamento em busca de segurança e regularidade, como o maquinista de vídeo de publicidade e cinema que compra notas fiscais dos colegas para prestar seu serviço como empresa (pessoa jurídica), mas aspira a um emprego assalariado qualificado.

O que se pode inferir é que as expectativas dos sujeitos têm extrapolado o modelo salarial, mas isso não significa que os mesmos não desejem segurança, boa remuneração ou estabilidade. Entretanto, parece que outros valores entram em jogo e com maior força. Há assim uma reorganização da hierarquia valorativa vinculada ao trabalho para os sujeitos. E o mais complicado é que não emerge uma nova hierarquia uníssona, mas uma multi- 
plicidade de possibilidades que ainda têm que ser reconstruídas pelas pesquisas. No trabalho industrial predominam a segurança, o status, a boa remuneração como valores fundamentais para vida boa. Esse modelo sofre rupturas, as quais são acompanhadas de mudanças culturais como o aumento pelas demandas de autenticidade e pela consolidação da ideia de autonomia operacional.

A proeminência da autonomia e da autenticidade nos formatos empreendedores não impediria em si a emergência de um mercado corresponsabilizado, ou seja, dotado de liberdade social, pois poderia haver políticas sociais que garantissem segurança e dignidade àqueles que aderem a essas novas formas de trabalho. Entretanto, o incentivo institucional a essas iniciativas têm como substrato ideológico o livre mercado e autorresponsabilização (Gaiger; Correa, 2010). Além disso, a autonomia e a autenticidade não têm incitado a mobilização, pois se tornaram valores em si mesmos, os quais foram traduzidos em imperativos morais inerentes à ação autoempreendedora, mesmo quando não resistem a uma análise do real. Ser gestor de si e a expressão subjetiva - em si mesma -, através do trabalho, enfraquecem a perspectiva de uma luta comum por uma pauta compartilhada e favorece as soluções individualizantes, o que fragiliza a realidade da liberdade social. Tais posturas diferem dos que seguem buscando as conquistas do assalariamento, pois nestes prevalece uma corresponsabilização da própria subsistência e dignidade, já que demandam do estado e do empregador segurança, estabilidade, boa remuneração salários etc.

Assim, mesmo que individualmente haja projetos libertadores, isso não se configura como um modelo para o social. Cabe, pois, perguntar: será que as formas de resistência que hoje se apresentam atomizadas só possibilitam a liberdade individual? Há realmente uma mudança na concepção do mercado de trabalho? Qual é a eticidade dessa esfera social? Lograr pensar a liberdade social para além do assalariamento é tarefa ainda a ser realizada.

\section{Considerações finais}

Honneth deu mais um importante passo para o seu projeto de renovar a Teoria Crítica, ao associar a meta de um reconhecimento recíproco - já não mais acionado basicamente nas experiências de desrespeito - ao normativo compartilhado nas instituições sociais. O intuito é romper com as teorias da justiça que adotam definições e critérios apriorísticos do justo e buscar esses valores na realidade social. Isso levaria a uma maior aproximação entre filosofia e práxis, entre teoria e realidade empírica. Entretanto, como apontado, há uma 
primazia, na reconstrução normativa, da teoria em detrimento da pesquisa empírica, pois o que é reconstruído são dimensões do real em conformidade com o projeto filosófico da Teoria Crítica.

Em Honneth, a predominância do normativo aparece de duas formas: (1) a reconstrução tem como fundamento uma ontologia do reconhecimento que se torna a norma universal para se pensar o justo, e assim, mesmo admitindo transformações no conteúdo ético da norma, o autor não questiona a própria norma e (2) tem como parâmetro o conteúdo ou a norma de liberdade social de um dado período, assim ignora uma multiplicidade de experiências nas quais emergem outros padrões normativos nas relações intersubjetivas. Neste sentido, se, de um lado, a reconstrução normativa é fundamental para identificar e analisar os valores eticamente institucionalizados na sociedade moderna, de outro, ela pode ser problematizada enquanto instrumento teórico-metodológico para explorar e aprofundar o conhecimento sobre a realidade empírica, tarefa fundamental das ciências sociais.

A zona cinzenta é indicada neste artigo como um exemplo deste tensionamento entre um modelo de justiça normativo e o real encontrado na pesquisa social. A busca de formas alternativas de inserção laboral, fora dos cânones outrora institucionalizados da sociedade salarial, tem tomado um formato individualizado e atomizado. Se por um lado constitui-se em alternativas individuais de autonomia, autenticidade e rompimento com a subordinação típica do trabalho assalariado, por outro, não é possível pensar essa busca como um projeto de liberdade social para todos. Assim, urge colocar a questão: dado que o surgimento de novas relações de trabalho, tal como o autoempreendedorismo, são consideradas anomalias no modelo honnethiano (já que não conduzem à socialização do mercado e tampouco rementem a um contexto de cooperação), como encontrar hoje a medida do justo? Ao se enquadrar essas experiências sob a primazia filosófica, perde-se a exploração das lógicas de ação dos sujeitos que a compõem, assim como das condições sociais sobre as quais emergiram. Neste sentido, o pressuposto racional - liberdade social - se sobrepõe ao real e o silencia. O maior desafio parece ser integrar o nível "micro" nessa teoria "macro" da justiça, visando ampliar as estruturas evidenciadas pelo autor, pois apesar do esquema conceitual honnethiano contribuir para aclarar repertórios de justificações de justiça, deixa em silêncio grande parte da realidade social no que tange à possibilidade de identificar valores emergentes para constituição do "novo" justo através de regras implícitas que possam apresentar um potencial emancipatório. 


\section{Referências}

ANDERSON, Joel; HONNETH, Axel. Autonomia, vulnerabilidade, reconhecimento e justiça. Cadernos de filosofia alemã, n. 17, p. 81-112, $2011<10.11606 /$ issn.23189800.v0i17p71-80>.

GAIGER, Luiz Inácio; CORRÊA, Andressa. O microempreendedorismo em questão: elementos para um debate necessário. Politica \& Sociedade, v. 9, p. 205-230, 2010.

HOLMES, Pablo. Briga de família ou ruptura metodológica na teoria crítica (Habermas x Honneth). Tempo Social, v. 21, n. 1, p. 133-155, $2009<10.1590 / \mathrm{S} 0103-$ $20702009000100008>$.

HONNETH, Axel. El derecho de la libertad: esbozo de uma eticidad democrática. Madrid: Katz, 2014.

HONNETH, Axel. A textura da justiça. Sobre os limites do procedimentalismo contemporâneo. Civitas, v. 9, n. 3, p. 345-368, $2009<10.15448 / 1984-7289.2009 .3$. 6896>.

HONNETH, Axel. La société du mépris: vers une nouvelle Théorie Critique. Paris: La Découverte-Gallimard, 2006.

HONNETH, Axel. Recognition and justice: outline of a plural theory of justice. Acta Sociologica, v. 47, n. 4, p. 351-364, $2004<10.1177 / 0001699304048668>$.

HONNETH, Axel. Luta por reconhecimento: a gramática social dos conflitos sociais. São Paulo: Editora 34, 2003.

HONNETH, Axel; FRASER, Nancy. Redistribución o reconocimiento? Espanha: Morata, 2006.

KESSELMANN, D.; AZAÏS, C. L'évolution des normes d'emploi et nouvelles formes d'inégalités: vers une comparaison des zones grises? Working paper, 2011, circulação restrita.

MELO, Rurion. Da teoria à práxis? Axel Honneth e as lutas por reconhecimento na teoria política contemporânea. Revista Brasileira de Ciência Política, n. 15, p. 17-36, $2014<10.1590 / 0103-335220141502>$.

RAVAGNANI, Herbert B. Uma introdução à teoria crítica de Axel Honneth. Intuitio, v. 2, n. 3, p. 51-67, 2009.

ROSENFIELD, Cinara; ALVES, Daniela A. Autonomia e trabalho informacional: o teletrabalho. Dados, v. 54, n. 1, p. 207-233, $2011<10.1590 / \mathrm{S} 0011-52582011$ $000100006>$.

ROSENFIELD, C. GIRAUD, O.; MOSSI, T. W.; REY, F. Empreendedorismo ou política de trabalho e emprego? Comparando Brasil e França. In: Cássio Calvete; Máris Gosmann (orgs.). Politicas de emprego, trabalho e previdência. Porto Alegre: Ufrgs, 2014. p. 181-203.

ROSENFIELD, Cinara; SAAVEDRA, Giovani. Reconhecimento, teoria crítica e sociedade: sobre desenvolvimento da obra de Axel Honneth e os desafios da sua aplicação no Brasil. Sociologias, v. 15, n. 33, p. 14-54, $2013<10.1590 /$ S151745222013000200002>. 
TAYLOR, Charles. La etica de la autenticidad. Barcelona: Ediciones Paidós, 1994.

TRIPIER, Pierre. La sociologie du travail à travers ses paradigmes. In: M. De Coster; F. Pichault (orgs.). Traité de sociologie du travail. Paris: De Boeck Université, 1998. p. $57-60$.

VOIROL, Olivier. Teoria crítica e pesquisa social: da dialética à reconstrução. Novos Estudos Cebrap, n. 93, p. 81-99, $2012<10.1590 /$ S0101-33002012000200007>.

Recebido em: 3 jul. 2015

Aprovado em: 1을. 2015

Autora correspondente:

Cinara L. Rosenfield

Av. Taquara 110/406

90460-210 Porto Alegre, RS, Brasil 